\title{
Association of a single nucleotide polymorphism in titin gene with marbling in Japanese Black beef cattle
}

\author{
Takahisa Yamada $^{\dagger 1}$, Seiki Sasaki ${ }^{\dagger 2}$, Shin Sukegawa ${ }^{\dagger 3}$, Sachiyo Yoshioka ${ }^{4}$, \\ Youichi Takahagi ${ }^{3}$, Mitsuo Morita ${ }^{2}$, Hiroshi Murakami ${ }^{3}$, Fumiki Morimatsu ${ }^{3}$, \\ Tatsuo Fujita ${ }^{5}$, Takeshi Miyake ${ }^{1}$ and Yoshiyuki Sasaki*4
}

\begin{abstract}
Address: ${ }^{1}$ Laboratory of Animal Breeding and Genetics, Graduate School of Agriculture, Kyoto University, Sakyo-ku, Kyoto 606-8502, Japan ${ }^{2}$ Maebashi Institute of Animal Science, Livestock Improvement Association of Japan, Maebashi, Gunma 371-0121, Japan, ${ }^{3}$ Research and Development Center, Nippon Meat Packers, Inc., Tsukuba, Ibaraki 300-2646, Japan, ${ }^{4}$ Kyoto Cattle Genetics Section, Beef Information \& Genetics Institute, Inc, Otsu, Shiga 520-0865, Japan and ${ }^{5}$ Cattle Embryo Transfer \& Genetics Section, Oita Prefectural Institute of Animal Industry, Takeda, Oita 878-0201, Japan

Email: Takahisa Yamada - tyamada@kais.kyoto-u.ac.jp; Seiki Sasaki - sasakis@liaj.or.jp; Shin Sukegawa - s.sukegawa@nipponham.co.jp; Sachiyo Yoshioka - sachiyoky@yahoo.co.jp; Youichi Takahagi - y.takahagi@nipponham.co.jp; Mitsuo Morita - morita@liaj.or.jp; Hiroshi Murakami - h.murakami@nipponham.co.jp; Fumiki Morimatsu -f.morimatsu@nipponham.co.jp; Tatsuo Fujita - fujitatatsuo@pref.oita.lg.jp; Takeshi Miyake - miyake@kais.kyoto-u.ac.jp; Yoshiyuki Sasaki* - sasaki@kra.biglobe.ne.jp

* Corresponding author †Equal contributors
\end{abstract}

Published: 7 May 2009

BMC Research Notes 2009, 2:78 doi:10.1 186/1756-0500-2-78
Received: 27 January 2009

Accepted: 7 May 2009

This article is available from: http://www.biomedcentral.com/1756-0500/2/78

(c) 2009 Sasaki et al; licensee BioMed Central Ltd.

This is an Open Access article distributed under the terms of the Creative Commons Attribution License (http://creativecommons.org/licenses/by/2.0), which permits unrestricted use, distribution, and reproduction in any medium, provided the original work is properly cited.

\begin{abstract}
Background: Marbling defined by the amount and distribution of intramuscular fat is an economically important trait of beef cattle in Japan. We have recently reported that single nucleotide polymorphisms (SNPs) in the endothelial differentiation, sphingolipid G-protein-coupled receptor, I (EDGI) gene were associated with marbling in Japanese Black beef cattle. As well as $E D G I$, the titin (TTN) gene, involved in myofibrillogenesis, has been previously shown to possess expression difference in musculus longissimus muscle between low-marbled and high-marbled steer groups, and to be located within genomic region of a quantitative trait locus for marbling. Thus TTN was considered as a positional functional candidate for the gene responsible for marbling. In this study, we explored SNP in TTN and analyzed association of the SNP with marbling.
\end{abstract}

Findings: A SNP in the promoter region of TTN, referred to as g.231054C $>T$, was the only difference detected between high- and low-marbled steer groups. The SNP was associated with marbling in 3 experiments using $10 \mathrm{I}$ sires $(P=0.004), 848$ paternal half-sib progeny steers from 5 sires heterozygous for the g.231054C>T $(P=0.046)$, and 820 paternal half-sib progeny steers from 3 sires homozygous for $C$ allele at the g.23 1054C>T $(P=0.05 \mathrm{I})$, in Japanese Black beef cattle. The effect of genotypes of the SNP on subcutaneous fat thickness was not statistically significant $(P>$ 0.05).

Conclusion: These findings suggest that in addition to the EDGI SNPs, the TTN SNP polymorphism is associated with marbling and may be useful for effective marker-assisted selection to increase the levels of marbling in Japanese Black beef cattle. Further replicate studies will be needed to confirm the allelic association observed here, and to expand the results to evaluate all possible genotypic combinations of alleles. 


\section{Background}

Marbling has an important effect on the economics of beef production [1-4]. Thus, it is greatly interesting to obtain better knowledge on the molecular architecture of marbling and to generate new opportunities for more effective marker-assisted selection.

The endothelial differentiation, sphingolipid G-protein-coupled receptor, 1 (EDG1) gene, which is involved in blood vessel formation [5], exhibited higher expression levels in highmarbled steer group than in low-marbled steer group in musculus longissimus muscle across all ages of the test period $[6,7]$. We have recently showed that single nucleotide polymorphisms (SNPs) in the EDG1 were associated with marbling in Japanese Black beef cattle [8].

From the result of our previous differential-display PCR (ddPCR) analysis in musculus longissimus muscle [6], the titin (TTN) gene exhibited higher expression levels in lowmarbled steer group than in high-marbled steer group in the late stage of the test period. Since TTN is known to be involved in myofibrillogenesis [9], the differential expression suggested that the decrease in the TTN expression might promote proliferation, differentiation, or maturation of adipocyte-lineage cells by weakening the structural integrity of the sarcomere, thereby resulting in high levels of marbling.

We have also located the TTN gene within genomic region of a quantitative trait locus for marbling $[10,11]$, which is mapped in a half-sib family of Japanese Black cattle to bovine chromosome 2 region [12]. Thus, the TTN gene was regarded as a positional functional candidate for the gene responsible for marbling.

\section{TTN gene structure}

We screened the NCBI bovine genome sequence database (National Center for Biotechnology Information, Bethesda, MD) with the publicly available bovine TTN cDNA sequence [GenBank:XR 027685] including
101,593 bp, and obtained 5,046,004-bp bovine genomic sequence [GenBank: NW 001494580] containing the TTN gene. By comparing the genomic and cDNA sequences, we showed that the bovine TTN gene spans $276,648 \mathrm{bp}$ and comprises $211 \mathrm{bp}$ of the first exon, 1,315 bp of the last exon, 100,067 bp of 313 internal exons, and 175,055 bp of 314 introns.

\section{SNP detection}

Two Holstein steers and two somatic nuclear-derived cloned steers [13] from a Japanese Black Itofuku sire with a very high estimated breeding value for marbling [14], which were assigned for low-marbled and high-marbled steer groups, respectively, in our previous ddPCR analysis [6], were used for SNP detection in this study. The two low-marbled Holstein steers and two high-marbled cloned steers were previously shown to have different TTN gene expression patterns [6]. The details of DNA samples from these steers were described previously [6]. We used two high-marbled cloned steers to confirm the authenticity of newly discovered SNP in the TTN gene.

PCR primers were designed to target $\sim 7$-kb proximal promoter and the first and last exon regions, to screen polymorphisms in the TTN gene between two low-marbled Holstein steers and two high-marbled cloned steers (Table 1). We selected these genomic regions for SNP detection, because it is likely that these regions are involved in TTN gene expression. PCR amplifications were performed using $25 \mathrm{ng}$ of the prepared DNA as template in a final volume of $100 \mu \mathrm{l}$ containing $1 \mu \mathrm{M}$ of each primer, 0.25 mM of each dNTP, 2.5 U of Go Taq polymerase (Promega, Madison, WI), and $1 \times$ Go Taq buffer (Promega). The PCR conditions were carried out as follows: $94^{\circ} \mathrm{C}$ for $2 \mathrm{~min}, 35$ cycles of $94^{\circ} \mathrm{C}$ for $30 \mathrm{~s}$, the annealing temperature indicated in Table 1 for $30 \mathrm{~s}$, and $72^{\circ} \mathrm{C}$ for $1 \mathrm{~min}$, followed by a further 5 -min extension at $72^{\circ} \mathrm{C}$. PCR products were examined by electrophoresis through a $1.0 \%$ agarose gel to determine the quality and quantity for DNA sequencing. DNA sequencing of PCR-amplified products was per-

Table I: Primers designed for SNP detection in the bovine TTN gene

\begin{tabular}{llll}
\hline Primer name & Sequence & Nucleotide position* & Annealing temperature \\
\hline TT-IF & 5'-TGCAGCCAAAGATGTAGAAGC-3' & $-7,203$ to $-7,183$ & $60^{\circ} \mathrm{C}$ \\
TT-IR & ''-TCAGTCCTTCCAATGAATACCC-3' & $-5,262$ to $-5,283$ & $60^{\circ} \mathrm{C}$ \\
TT-2F & 5'-GTCATGTATGGATGAGAGTTGGA-3' & $-5,428$ to $-5,406$ & $59^{\circ} \mathrm{C}$ \\
TT-2R & 5'-GAGAGTCGGACACGACTGAA-3' & $-3,487$ to $-3,506$ & $59^{\circ} \mathrm{C}$ \\
TT-3F & 5'-GCCATTAAATGTGTGCGTGA-3' & $-3,618$ to -3,599 & $60^{\circ} \mathrm{C}$ \\
TT-3R & 5'-TTGTGCACGTGTGTGTATGG-3' & $-1,674$ to $-1,693$ & $60^{\circ} \mathrm{C}$ \\
TT-4F & ''-TTCCCATAAGAATTAAAGTGGTTTG-3' & $-1,806$ to - 1,782 & $59^{\circ} \mathrm{C}$ \\
TT-4R & 5'-GATAGCACCAAGTAGTCCGACA-3' & 329 to 308 & $59^{\circ} \mathrm{C}$ \\
TT-5F & 5'-CCTAAGAGGTGAGCAATCCA-3' & 275,190 to 275,209 & $58^{\circ} \mathrm{C}$ \\
TT-5R & 5'-GCTGTAGAGAACTTGAGTTGC-3' & 276,756 to 276,736 & $58^{\circ} \mathrm{C}$
\end{tabular}

*The nucleotide positions of primers are shown according to their location relative to the putative transcription initiation site of the TTN gene. 
formed by the direct sequencing with an $\mathrm{ABI} 377$ sequencer (ABI, Foster City, CA) following standard Big Dye protocols (ABI). Primers used for PCR amplifications and obtained from primer walking were used as sequencing primers. Nucleotide polymorphisms were identified by comparison of sequence traces between the 2 steer groups, and designated according to nomenclature for the description of sequence variations in the HGVS (Human Genome Variation Society, Fitzroy, VIC, Australia) [15].

We sequenced the 6,615-bp 5' flanking region, the 211-bp first exon region, and the 1,315-bp last exon region of the TTN gene for the 4 DNA samples. This sequence analysis revealed only one SNP in the TTN gene between the 2 steer groups: a $\mathrm{C}$ to $\mathrm{T}$ transition located 652 bp upstream of the putative transcription initiation site in the promoter region $(g .231054 C>T)$. The g.231054C $>T$ has been submitted to the dbSNP with ss accession number 120037472. The two Holstein steers were homozygous for $C$ allele at the g.231054C>T site, whereas the two cloned steers heterozygous for $C$ and $T$ alleles at the g. 231054C>T site.

\section{Association study}

Samples and data

We performed 3 experiments for association of the g.231054C $>T$ with marbling and subcutaneous fat thickness. We used 101 Japanese Black sires in experiment 1. The sires used to be or are used in the Oita Prefectural Institute of Animal Industry (Oita, Japan). There was no strong bias for a specific father or a specific maternal grandfather of the sires, and the sire panel likely represents a variety of the sire lines. In experiment 2,848 paternal half-sib Japanese Black progeny steers (55 to 445 steers per sire) produced from 5 sires heterozygous for the g.231054C>T, with dams considered to represent a random sample of the female population, were used. We used 820 paternal half-sib Japanese Black progeny steers (88 to 535 steers per sire) produced from 3 sires homozygous for $C$ allele at the g.231054C $>T$, with dams considered to be a random mating population, in experiment 3 . These progeny steers (in experiments 2 and 3 ) were fattened, and shipped to the carcass market in the Oita prefecture. Semen or blood of the sires and adipose tissues of the progeny steers were collected for SNP genotyping. DNA samples were prepared from the materials according to standard protocols.

The predicted breeding values of the sires and the progeny steers for marbling score and subcutaneous fat thickness were obtained from the Oita recording system for beef cattle reported by Sasaki et al. [16], and used as phenotypic values in this study. In the recording system, the breeding values were predicted from carcass records of Japanese Black steers and heifers, fattened in the Oita prefecture.
The fattened animals were shipped to various carcass markets from 1988 to 2003, where they were slaughtered and their carcasses evaluated. The data were edited to connect across subclasses such that each market-year subclass had 50 or more animals and each farm had 10 or more animals. The final number of animals was 48,045 , and there were 89 market-year subclasses, 332 farms, and 228 sires.

Marbling score and subcutaneous fat thickness were measured on carcasses dissected at the sixth and seventh rib section, according to the Japanese meat grading system by certified graders from the Japan Meat Grading Association (Tokyo, Japan) [4]. Marbling score was scored from 1 to 12 (beef marbling standard number) with a standard model panel, in which higher scores correspond to more marbling. Score 1 likely corresponds to "Practically Devoid", "Traces", "Slight" and "Small", score 2 or 3 "Modest", "Moderate" and "Slightly Abundant", and score 4 or 5 "Moderately Abundant". Subcutaneous fat thickness was measured at the rib interface perpendicular to the outside surface at a point 3 -fourths the length of the longissimus muscle from its chine bone end.

Data were analyzed by the REML method using the MTDFREML programs [17], and genetic and environmental variances were estimated. The BLUP option in the programs using the estimated variance components was chosen to predict the breeding values of animals with a single trait model. Sex, market-year, and farm were considered fixed effects. Fattening period and slaughter age were also considered as up to quadratic covariates. The fattening period denotes the period from the start of fattening to shipping to market for each animal. These fixed effects were all significant $(P<0.001)$. Random effects included additive genetic effect of the individuals; that is, the animal model was adopted to predict the breeding values.

This study conformed to the guidelines for animal experimentation of the Graduate School of Agriculture, Kyoto University (Kyoto, Japan).

\section{SNP genotyping}

The g.231054C>T was genotyped using PCR-restriction fragment length polymorphism (RFLP) method. PCR primers used for PCR-RFLP were 5'-TCATCTCCTAACTACTTCCCA-3' and 5'-ACAAAATCTGAACCTGGCTT-3' (Nucleotide positions relative to the putative transcription initiation site of the TTN gene were -842 to -822 and -616 to -635 , respectively). PCR amplifications were carried out as described in SNP detection section, using a final volume of $20 \mu \mathrm{l}$ and the annealing temperature of $55^{\circ} \mathrm{C}$. An aliquot of PCR-amplified products was digested at $37^{\circ} \mathrm{C}$ for $1 \mathrm{~h}$ with restriction enzyme HpyCH4III, and electrophoresed on a 3.0\% agarose gel. Agarose gels were stained with ethidium bromide and photographed under 
an ultraviolet light. Using this method, 227-bp PCR fragments containing the SNP site were amplified, and HpyCH4III-digested into 36- and 191-bp fragments at the $C$ allele, but not at the $T$ allele: the $C C$ homozygotes, the TT homozygotes, and the CT heterozygotes resulted in 2 bands (36 and $191 \mathrm{bp}$ ), 1 band (227 bp), and 3 bands (36, 191, and $227 \mathrm{bp})$.

\section{Experiment 1}

Genotyping 101 sires for the g.231054C>T revealed 50 animals homozygous for $C$ allele, 47 animals heterozygous for $C$ allele and $T$ allele, and 4 animals homozygous for $T$ allele. The 4 TT homozygotes were too small sample size to give reliable estimates, and then excluded from our statistical analysis. Statistically significant differences among the genotypes of the SNP were detected for marbling $(P=0.004)$, but not for subcutaneous fat thickness $(P=0.984)$, by the analysis with the model that included the SNP genotype as the fixed effect and the sire (father of the sire) as the random effect (Table 2 ). The marbling score was significantly higher in the $C T$ heterozygotes than in the CC homozygotes (Table 2).

\section{Experiment 2}

To better estimate the effect of the g.231054C>T T allele on marbling and subcutaneous fat thickness, we performed experiment 2 . The interaction between the SNP genotype and the sire was not statistically significant $(P=$ 0.320 for marbling, and $P=0.192$ for subcutaneous fat thickness) in the model that included the SNP genotype and the sire as the fixed effects and their interaction, and was excluded from our statistical model. In the model without the interaction effect, the SNP genotype had the statistically significant effect on marbling $(P=0.046)$, but not subcutaneous fat thickness $(P=0.749)$ (Table 3$)$. The marbling score was significantly higher in the TT homozygotes than in the CC homozygotes, and that of the heterozygotes intermediate between those of the 2 homozygotes (Table 3 ).

\section{Experiment 3}

To further verify the association of the g.231054C $>T$ with marbling, we carried out experiment 3 . The steers in this experiment could be grouped only according to the alleles that they received from their dams, which are considered to be a random sample of a general population in Japanese Black beef cattle. Therefore, this experiment likely allowed a linkage disequilibrium estimate of the effect of the SNP. The interaction between the SNP genotype and the sire was not statistically significant $(P=0.208$ for marbling, and $P=0.980$ for subcutaneous fat thickness) in the model that included the SNP genotype and the sire as the fixed effects and their interaction, and was excluded from our statistical model. In the model without the interaction effect, the SNP genotype effect reached marginal significance $(P=0.051)$ for marbling, but not for subcutaneous fat thickness $(P=0.310)$ (Table 4$)$. The marbling score exhibited a tendency to be higher in the CT heterozygotes than in the CC homozygotes (Table 4).

Based on 3 experiments, we showed that the g.231054C>T is associated with marbling in Japanese Black beef cattle, with the $T$ allele resulting in high levels of marbling. Especially, in experiments 2 and 3, because the dams can be considered to represent a random sample of the Japanese Black population, the association is likely to be true. We used the predicted breeding values as phenotypic values, and then sire contributions to the predicted breeding values were the same for all offspring, even if the heterozygous sires were used in experiment 2 . Thus, it is likely to be desirable to use larger numbers of dams in the analyses using paternal half-sib progeny steers such as experiments 2 and 3 . We should note that the experiments in this study were the case. Further, the association of the g.231054C>T with marbling was corroborated by an independent study using 104 paternal half-sib Japanese Black families with a total of 821 progeny steers (S. Sukegawa, unpublished data).

Based on the association of the g.231054C>T with marbling, together with TTN expression difference between low-marbled (with g.231054C>T C allele) and high-marbled steer groups (with g.231054C>T C and $T$ alleles) and co-localization of the marbling quantitative trait locus with the TTN, we can hypothesize that the SNP in the promoter region might have an impact on TTN expression and also marbling by affecting TTN promoter activity. However, the SNP is not located within any of as yet identified canonical sequences involved in gene transcription. Thus, a more likely event is that the TTN SNP is in linkage

Table 2: Effect of the SNP genotypes on marbling and subcutaneous fat thickness in experiment I

\begin{tabular}{|c|c|c|c|}
\hline \multirow[b]{2}{*}{ Genotype } & \multirow[b]{2}{*}{ No. of animals } & \multicolumn{2}{|c|}{ Breeding value* } \\
\hline & & Marbling score & Subcutaneous fat thickness (mm) \\
\hline$C T$ & 47 & $2.8 \mathrm{I}^{\mathrm{a}} \pm 0.25$ & $-2.85 \pm 0.74$ \\
\hline CC & 50 & $2.13^{b} \pm 0.23$ & $-2.84 \pm 0.80$ \\
\hline
\end{tabular}

*The breeding values are given as estimates \pm SE.

a, bEstimates at different genotypes without a common letter in their superscripts significantly differ $(P<0.0 \mathrm{I})$. 
Table 3: Effect of the SNP genotypes on marbling and subcutaneous fat thickness in experiment 2

\begin{tabular}{|c|c|c|c|}
\hline \multirow[b]{2}{*}{ Genotype } & \multirow[b]{2}{*}{ No. of animals } & \multicolumn{2}{|c|}{ Breeding value* } \\
\hline & & Marbling score & Subcutaneous fat thickness $(\mathrm{mm})$ \\
\hline$T T$ & 149 & $3.42^{\mathrm{a}} \pm 0.08$ & $-0.33 \pm 0.36$ \\
\hline$C T$ & 378 & $3.22^{b} \pm 0.06$ & $-0.22 \pm 0.25$ \\
\hline$C C$ & 321 & $3.19 b \pm 0.06$ & $-0.05 \pm 0.27$ \\
\hline
\end{tabular}

*The breeding values are given as least squares means \pm SE.

a, bMeans at different genotypes without a common letter in their superscripts significantly differ $(P<0.05)$.

Table 4: Effect of the SNP genotypes on marbling and subcutaneous fat thickness in experiment 3

\begin{tabular}{|c|c|c|c|}
\hline \multirow[b]{2}{*}{ Genotype } & \multirow[b]{2}{*}{ No. of animals } & \multicolumn{2}{|c|}{ Breeding value* } \\
\hline & & Marbling score & Subcutaneous fat thickness $(\mathrm{mm})$ \\
\hline$C T$ & 270 & $2.88 \pm 0.06$ & $-0.04 \pm 0.24$ \\
\hline CC & 550 & $2.76 \pm 0.04$ & $0.23 \pm 0.18$ \\
\hline
\end{tabular}

$*$ The breeding values are given as least squares means \pm SE.

disequilibrium with an unidentified and truly relevant mutation, rather than functional and a causal mutation for marbling.

The effect of genotypes of the SNP was not statistically significant $(P>0.05)$ for subcutaneous fat thickness. Further, the marbling quantitative trait locus corresponding to chromosomal position of the TTN did not have statistically significant effect on subcutaneous fat thickness $[10,11]$. Thus, it is likely that the TTN SNP is not associated with subcutaneous fat thickness in Japanese Black beef cattle. This might be supported by the fact that Japanese Black breed exhibits low genetic correlation between marbling and subcutaneous fat thickness [7].

Several previous studies have reported polymorphisms associated with beef marbling using beef cattle breeds other than Japanese Black [18-27]. We have recently reported that SNPs in the EDG1 gene were associated with marbling in Japanese Black breed [8]. Thus, our present study seems to be the second report to show polymorphisms associated with marbling using Japanese Black breed.

The information on the TTN SNP obtained in this study, as well as the EDG1 SNPs, may be applied to effective marker-assisted selection to increase the levels of marbling in Japanese Black beef cattle. Further replicate studies will be needed to confirm the allelic association observed here, and to expand the results to evaluate all possible genotypic combinations of alleles.

\section{Competing interests}

The authors declare that they have no competing interests.

\section{Authors' contributions}

TY carried out the statistical analyses and drafted the manuscript. SS, SS, SY, and YT carried out the SNP detection and genotyping. MM, HM, FM, and TF participated in the sample and data collection. TM carried out further statistical analyses. YS participated in the design and coordination of the study and helped to draft the manuscript. All authors read and approved the final manuscript.

\section{Acknowledgements}

This work was supported by a Grant-in-Aid for Scientific Research (B) (no. 14360166) from the Ministry of Education, Science, Sports, and Culture of Japan, and by the research funds of Japanese Livestock Technology Association.

\section{References}

I. Boylston TD, Morgan SA, Johnson KA, Busboom JR, Wright RW Jr Reeves J]: Lipid content and composition of Wagyu and domestic breeds of beef. J Agric Food Chem 1995, 43: I 202-I 207.

2. Busboom JR, Jeremiah LE, Gibson LL, Johnson KA, Gaskins CT, Reeves JJ, Wright RW Jr: Effects of biological source on cooking and palatability attributes of beef produced for the Japanese market. Meat Sci 1993, 35:24I-258.

3. Matsuishi M, Fujimori M, Okitani A: Wagyu beef aroma in Wagyu (Japanese Black cattle) beef preferred by the Japanese over imported beef. Anim Sci J 200I, 72:498-504.

4. Japan Meat Grading Association: New Beef Carcass Grading Standards Tokyo, Japan: Japan Meat Grading Association; 1988.

5. Liu Y, Wada R, Yamashita T, Mi Y, Deng CX, Hobson JP, Rosenfeldt HM, Nava VE, Chae SS, Lee MJ, Liu CH, Hla T, Spiegel S, Proia RL: Edg-I, the G protein-coupled receptor for sphingosine-Iphosphate, is essential for vascular maturation. J Clin Invest 2000, 106:95|-96I. 
6. Sasaki $Y$, Nagai K, Nagata $Y$, Doronbekov K, Nishimura S, Yoshioka S, Fujita T, Shiga K, Miyake T, Taniguchi Y, Yamada T: Exploration of genes showing intramuscular fat deposition-associated changes in musculus longissimus muscle. Anim Genet 2006, 37:40-46.

7. Sasaki Y, Yamada T, Miyake T: Quantitative and molecular genetic approaches for the improvement of carcass traits in the Wagyu cattle. In Proceedings of the 8th World Congress on Genetics Applied to Livestock Production: 13-18 August 2006; Belo Horizonte, MG, Brazil Edited by: Madalena FE. Belo Horizonte MG, Brazil: Federal University of Minas Gerais; 2006:13-0I.

8. Yamada T, Itoh M, Nishimura S, Taniguchi Y, Miyake T, Sasaki S, Yoshioka S, Fujita T, Shiga K, Morita M, Sasaki Y: Association of single nucleotide polymorphisms in endothelial differentiation, sphingolipid G-protein-coupled receptor, I gene with marbling in Japanese Black beef cattle. Anim Genet 2009, 40:209-216.

9. Itoh-Satoh M, Hayashi T, Nishi H, Koga Y, Arimura T, Koyanagi T, Takahashi M, Hohda S, Ueda K, Nouchi T, Hiroe M, Marumo F, Imaizumi T, Yasunami M, Kimura A: Titin mutations as the molecular basis for dilated cardiomyopathy. Biochem Biophys Res Commun 2002, 291:385-393.

10. Takasuga A, Watanabe T, Mizoguchi Y, Hirano T, Ihara N, Takano A, Yokouchi K, Fujinaka A, Chiba K, Kobayashi N, Tatsuda K, Oe T, Furukawa-Kuroiwa M, Nishimura-Abe A, Fujita T, Inoue K, Mizoshita $K$, Ogino A, Sugimoto $Y$ : Identification of bovine QTL for growth and carcass traits in Japanese Black cattle by replication and identical-by-descent mapping. Mamm Genome 2007, I8:125-136.

II. Watanabe T, Takasuga A, Mizoguchi Y, Hirano T, Ihara N, Takano A, Yokouchi K, Fujinaka A, Chiba K, Kobayashi N, Tatsuda K, Oe T, Furukawa M, Nishimura-Abe A, Imai K, Fujita T, Nagai S, Inoue K, Mizoshita K, Ogino A, Sugimoto Y: A comprehensive QTL map of Japanese Black cattle (Wagyu). In Proceedings of the 29th International Conference on Animal Genetics: II-16 September 2004; Tokyo, Japan Edited by: Sasaki Y. Kyoto, Japan: Kyoto University; 2004: 136.

12. Yamada T, Taniguchi Y, Nishimura S, Yoshioka S, Takasuga A, Sugimoto $Y$, Sasaki Y: Radiation hybrid mapping of genes showing intramuscular fat deposition-associated expression changes in bovine musculus longissimus muscle. Anim Genet 2006, 37: $184-185$.

13. Shiga K, Fujita T, Hirose K, Sasae Y, Nagai T: Production of calves by transfer of nuclei from cultured somatic cells obtained from Japanese Black bulls. Theriogenology 1999, 52:527-535.

14. Oita Prefectural Institute of Animal Industry: Sire Summary Oita, Japan: Oita Prefectural Institute of Animal Industry; 1999.

15. Nomenclature for the description of sequence variations [http://www.hgvs.org/mutnomen/]

16. Sasaki Y, Miyake T, Gaillard C, Oguni T, Matsumoto M, Ito M, Kurahara T, Sasae Y, Fujinaka K, Ohtagaki S, Dougo T: Comparison of genetic gains per year for carcass traits among breeding programs in the Japanese Brown and the Japanese Black cattle. JAnim Sci 2006, 84:317-323.

17. Boldman KG, Kriese LA, Van Vleck LD, Van Tassell CP, Kachman SD: A Manual for Use of MTDFREML, A Set of Programs to Obtain Estimates of Variances and Covariances Washington, DC: Agricultural Research Service, United States Department of Agriculture; 1995.

18. Barendse W: Assessing lipid metabolism. In Patent, International Publication Number: WO 99/23248 World International Property Organization; 1999.

19. Barendse W, Bunch RJ, Harrison BE, Thomas MB: The growth hormone I GHI:c.457C>G mutation is associated with intramuscular and rump fat distribution in a large sample of Australian feedlot cattle. Anim Genet 2006, 37:211-214.

20. Barendse W, Bunch RJ, Kijas JW, Thomas MB: The effect of genetic variation of the retinoic acid receptor-related orphan receptor C gene on fatness in cattle. Genetics 2007, 175:843-853.

21. Buchanan FC, Fitzsimmons CJ, Van Kessel AG, Thue TD, WinkelmanSim DC, Schmutz SM: Association of a missense mutation in the bovine leptin gene with carcass fat content and leptin mRNA levels. Genet Sel Evol 2002, 34: 105-1/6.

22. Casas E, Bennett GL, Smith TP, Cundiff LV: Association of myostatin on early calf mortality, growth, and carcass composition traits in crossbred cattle. J Anim Sci 2004, 82:2913-2918.

23. Hale CS, Herring WO, Shibuya H, Lucy MC, Lubahn DB, Keisler DH, Johnson GS: Decreased growth in Angus steers with a short
TG-microsatellite allele in the PI promoter of the growth hormone receptor gene. J Anim Sci 2000, 78:2099-2I 04

24. Jiang Z, Kunej T, Michal JJ, Gaskins CT, Reeves JJ, Busboom JR, Dovc P, Wright RW Jr: Significant associations of the mitochondrial transcription factor A promoter polymorphisms with marbling and subcutaneous fat depth in Wagyu $\times$ Limousin F2 crosses. Biochem Biophys Res Commun 2005, 334:5I 6-523.

25. Michal JJ, Zhang ZW, Gaskins CT, jiang Z: The bovine fatty acid binding protein 4 gene is significantly associated with marbling and subcutaneous fat depth in Wagyu $\times$ Limousin F2 crosses. Anim Genet 2006, 37:400-402.

26. Nkrumah JD, Li C, Yu J, Hansen C, Keisler DH, Moore SS: Polymorphisms in the bovine leptin promoter associated with serum leptin concentration, growth, feed intake, feeding behavior, and measures of carcass merit. J Anim Sci 2005, 83:20-28.

27. Thaller G, Kuhn C, Winter A, Ewald G, Bellmann O, Wegner J, ZuhIke H, Fries R: DGATI, a new positional and functional candidate gene for intramuscular fat deposition in cattle. Anim Genet 2003, 34:354-357.
Publish with BioMed Central and every scientist can read your work free of charge

"BioMed Central will be the most significant development for disseminating the results of biomedical research in our lifetime. "

Sir Paul Nurse, Cancer Research UK

Your research papers will be:

- available free of charge to the entire biomedical community

- peer reviewed and published immediately upon acceptance

- cited in PubMed and archived on PubMed Central

- yours - you keep the copyright
BioMedcentral 